\title{
BREAKUP OF ROUND NONTURBULENT LIQUID JETS IN GASEOUS CROSSFLOWS
}

\author{
K.A.Sallam, ${ }^{*}$ C. Aalburg ${ }^{*}$ and G.M. Faeth ${ }^{\dagger}$
}

\begin{abstract}
An experimental investigation of the primary breakup of nonturbulent round liquid jets in gas crossflow is described. Pulsed shadowgraph and holograph observations of jet primary breakup regimes, conditions for the onset of breakup, properties of waves observed along the liquid surface, drop sue and velocity properties resulting from breakup and conditions required for the breakup of the liquid column as a whole, were obtained for air crossflows at normal temperature and pressure. When combined with the earlier studies of Mazallon et al. (1999), the test range included crossflow Weber numbers of 0 2000, liquidgas momentum ratios of 100-8000, liquidgas density ratios of 683-1021, and Ohnesorge numbers of $0.003-0.12$. The results suggest qualitative similarities between the primary breakup of nonturbulent round liquid jets in crossflows and the secondary breakup of drops subjected to shock wave disturbances (e.g., bag, multimode and shear breakup regimes are observed in both instances) with relatively little effect of the liquidgas momentum ratio on breakup properties over the present test range. Effects of liquid viscosity were also small for present observations where Ohnesorge numbers were less than 0.4. Phenomenological analyses were successful for helping to interpret and correlate the properties of primary breakup of round liquid jets in gas crossflows that were measured during the present investigation.
\end{abstract}

*ResearchFellow, Department of Aerospace Engineering.

${ }^{\dagger}$ A.B. Modine Professor, Department of Aerospace Engineering, Fellow AIAA, Corresponding author, Tel.: +1-734-764-7202;Fax: +1-734-936-0106; E.mail address: gmfaeth@,umich.edu(G.M. Faeth).

Copyright (c) 2003 by G.M. Faeth. Published by the American Institute of Aeronautics and Astronautics, Inc., with permission.

\section{NOMENCLATURE}

$\mathrm{C}_{\mathrm{c}}=$ empirical constant

$\mathrm{C}_{\ell \mathrm{i}}=$ empirical constant

C, = empirical constant

$\mathrm{C}_{\mathrm{pi}}=$ empirical constant

$\mathrm{C}_{\mathrm{xb}}=$ empirical constant

$\mathrm{C}_{\mathrm{y}}=$ empirical constant

$\mathrm{C}_{\mathrm{yb}}=$ empirical constant

$\mathrm{C}_{\mathrm{D}}=$ drag coefficient

$\mathrm{d}_{\mathrm{i}}=$ streamwise jet diameter at onset of drop formation

$\mathrm{dj}=$ liquidjet diameter at jet exit

$\mathrm{d}_{\ell \mathrm{i}}=$ diameter of ligaments at liquidjet surface

$\mathrm{d}_{\mathrm{p}}=$ diameter of drops formed by primary breakup

$\mathrm{Oh}=$ Ohnesorge number, $\mu_{\mathrm{L}} /\left(\rho_{\mathrm{L}} \mathrm{d}_{\mathrm{j}} \sigma\right)^{1 / 2}$

$\mathrm{q}=$ flow momentum ratio, $\rho_{\mathrm{L}} \mathrm{v}_{\mathrm{j}}{ }^{2} /\left(\rho_{\mathrm{G}} \mathrm{u}_{\infty}{ }^{2}\right)$

$\mathrm{t} \quad-$ time

$\mathrm{t}^{*}=$ characteristic time, $\mathrm{d}_{\mathrm{j}}\left(\rho_{\mathrm{L}} / \rho_{\mathrm{G}}\right)^{1 / 2} / \mathrm{u}_{\infty}$

$\mathrm{u}=$ crosstream velocity

$v=$ streamwise velocity

$\mathrm{We}=$ Weber number, $\rho_{\mathrm{G}} \mathbf{d}_{\mathrm{j}} \mathrm{u}_{\mathrm{o}}{ }^{2} / \sigma$

$\mathrm{x}=$ crosstream distance

$\mathrm{y}_{\mathrm{c}}=$ critical streamwise distance for ligament properties

$\mathrm{y}=$ streamwise distance

$\lambda_{c}=$ wavelength for liquid column waves

$\lambda_{\mathrm{s}}=$ wavelength for liquid surface waves

$\mu=$ molecular viscosity

$v \quad=$ molecular kinematic viscosity

$\rho=$ density

$\sigma \quad=$ surface tension

Subscripts

$\mathrm{b}=$ location of breakup of entire liquid jet

$\mathrm{G}=$ gasproperty

$\mathrm{i}=$ location of onset of breakup

$\mathrm{j} \quad=$ jet exit property

$\ell=$ ligamentproperty

$\mathrm{L}=$ liquid property 


$$
\begin{aligned}
\mathrm{p} \quad= & \text { property of drops formed by primary } \\
& \text { breakup } \\
\infty \quad= & \text { ambient gas property }
\end{aligned}
$$

\section{INTRODUCTION}

The deformation and primary breakup properties of nonturbulent round liquid jets in gas crossflows were studied experimentally. The investigation was motivated by applications of spray breakup in crossflow to air-breathing propulsion systems, liquid rocket engines, diesel engines, spark ignition engines, and agricultural sprays, among others. The main objectives were to extend the recent observations of Mazallon et al. [1] in order to evaluate their findings about breakup regimes and some properties of primary breakup along the liquid surface, and to provide more information about the drop properties resulting from gas crossflows acting on nonturbulent round liquid jets. Methods of injector design and experimental observations were similar to past work in this laboratory, see Mazallon et al. [1] and references cited therein.

Earlier studies of nonturbulent round liquid jets in gas crossflows were recently reviewed by $\mathrm{Wu}$ et al. [2]; therefore, the following discussion of early work will be brief. Initial research on nonturbulent round liquid jets in gas crossflows mainly concentrated on the penetration lengths and the jet/spray plume trajectories for various flow conditions [3-14]. The primary liquid breakup properties of liquid jets in crossflow have recently received more attention, however, with Mazallon et al. [1], Wu et al. [2], and references cited therein, reporting similarities between the primary breakup properties of round liquid jets in gas crossflows and the secondary breakup properties of drops subjected to shock wave disturbances. Both Mazallon et al. [13 and Wu et al. [2], observed bag, multimode and shear breakup regimes along the liquid column in addition to breakup of the entire liquid column itself; they also identify conditions required for the onset of liquid surface and liquid column breakup mechanisms. The deformation properties of the liquid jet prior to breakup, the properties of waves formed along the liquid surface, and the trajectory properties of the liquid jet as a whole were also considered in Refs. 1 and 2.

The objectives of the present investigation were to extend the studies of both Mazallon et al. [1] and $\mathrm{Wu}$ et al. [2] by observing the properties of uniform nonturbulent round liquid jets in uniform gas crossflows, seeking to quantify effects of parameters known to influence the properties of primary breakup of nonturbulent round liquid jets in gas crossflows. Present observations included pulsed shadowgraph and holograms of nonturbulent round liquid jets of various liquids (water, ethyl alcohol, and a glycerol mixture) in air crossflows at normal temperature and pressure. The shadowgraph and holograms were used for flow visualization and to provide new information about jet primary breakup regimes, conditions for the onset of breakup along the liquid surface, the properties of liquid surface waves along the liquid surface, the properties of drop velocities after primary breakup, the properties of ligaments and drops due to primary breakup, and the properties of breakup of the entire liquid column.

\section{EXPERIMENTAL METHODS}

\section{$\underline{\text { Apparatus }}$}

The experiments were carried out in a rectangular shock tube with the driven section having a width of $38 \mathrm{~mm}$ and a height of $64 \mathrm{mtn}$. The driven section was open to the atmosphere and had windowed side walls in order to provide optical access, see the sketch of the test section in Fig. 1. The shock tube was sized to provide test times of 17$21 \mathrm{~ms}$ in the uniform flow region behind the shock wave. Crossflow velocities of $11-142 \mathrm{~m} / \mathrm{s}$ were considered, which involved nearly normal temperature and pressure conditions in the crossflow.

The nonturbulent round liquid jets were injected vertically downward using a pressure feed system as illustrated in Fig. 1. The test liquid was contained within a cylindrical test chamber having a diameter of $50 \mathrm{~mm}$ and a length of $100 \mathrm{~mm}$, constructed of type 304 stainless steel. The nozzle was located along the axis at the bottom of the test chamber. Round supercavitating nozzles were used that had sharp edged inlets and exits, with length-todiameter ratios less than 3 . This arrangement yields uniform nonturbulent round liquid jets as discussed by Wu et al. [15] and Lienhard [16]. Different supercavitating nozzles were used having diameters of $0.5,1.0$ and $2.0 \mathrm{~mm}$. Actual liquid jet diameters at the exit of the nozzles were found from shadowgraph; these diameters were only $50-70 \%$ of the geometrical nozzle exit diameters of the supercavitating nozzles, as discussed by Lienhard [16].

The test liquid was placed within the test chamber using the liquid fill line (note that surface tension acted naturally to prevent premature outflow 
of liquid). Pressurized air was admitted to the top of the test chamber upon activation of a solenoid valve in order to initiate flow of the liquid jet. The air used to pressurize the injected liquid was stored in a large $\left(1.3 \mathrm{~m}^{3}\right.$ volume) air reservoir set to the desired injection pressure by filling from the laboratory highpressure air supply system (air supply system pressures were up to $1500 \mathrm{kPa}$, with dewpoints less than $240 \mathrm{~K}$ ). The increased pressure in the test chamber than caused liquid outflow through the nozzle. Excessive aeration of the test liquid by the pressuring air during liquid jet injection was prevented by a baffle across the air inlet of the cylindrical chamber. Once all the liquid was forced out of the test chamber, the solenoid valve was closed and the test chamber was allowed to vent into the shock tube (and thus into the surrounding atmosphere). The test chamber was then refilled for the next test. The pressure of the air in the test chamber was vaned to provide liquid velocities at the jet exit of $10-45 \mathrm{~m} / \mathrm{s}$. Test times were short, however, this was not a problem because flow development times (taken as the time required for a given liquid sample to cross the shock tubes) were smaller than 7 ms which were less than $1 / 3$ of the available test times. In addition, data acquisition times using pulsed shadowgraphy and holography were even shorter, less than $10 \mathrm{~ns}$, and did not impose any significant test time requirements. Finally, timing of the breaking of the diaphragm of the shock tube and starting the liquid jet flow was controlled so that the jet flow was present, with the liquid jet passing out of the shock tube without splashing through a hole in the bottom of the tube just opposite the nozzle location. Naturally, once the crossflow was present, deflection of the jet caused it to strike the lower inside surface of the shock tube downstream of the hole, however, this was not a problem because the crossflow swept the splashed liquid downstream away from the liquid jet so that observations of the liquid jet itself were not obscured by splashed liquid.

\section{$\underline{\text { Instrumentation }}$}

Pulsed holography and shadowgraphy were used to observe the properties of the round liquid jet and the ligaments and drops produced by primary breakup, as a function of position along the liquid jet, for various liquid jet and crossflow test conditions. The arrangements of the shadowgraphy and holography systems were qualitatively similar to earlier work using the present shock tube facility to study the secondary breakup of drops [17-22] with the present configuration being specifically identical to that of Chou et al. [20]. Both measurements used two frequency-doubled YAG lasers (Spectra Physics Model GCR-130, $532 \mathrm{~nm}$ wavelength, $7 \mathrm{~ns}$ pulse duration, up to $300 \mathrm{~mJ}$ per pulse) which could be fired with pulse separations as small as $100 \mathrm{~ns}$. An off-axis holocamera arrangement was used with the optics providing a $25 \mathrm{~mm}$ diameter field of view at the test liquid column location. Reconstruction of the double-pulse holograms yielded two images of the flow so that liquid surface and drop velocities could be found given the time of separation between the pulses (which was measured with a digital oscilloscope). The second laser pulse was somewhat weaker than the first, which allowed directional ambiguity to be resolved because stronger pulses yielded sharper reconstructed images. The same arrangement provided shadowgraphy by blocking the reference beam.

The hologram reconstruction system involved a helium-neon laser (Spectra Physics Model $124 \mathrm{~B}$, cw laser, $35 \mathrm{~mW}$ of optical power) with the reconstructed image observed using a CCD camera (Sony, Model XC-77) with optics to yield a magnification of $300: 1$ and a field of view of the image on the monitor of $1.2 \times 1.4 \mathrm{~mm}$. The optical data was obtained using a frame grabber (Data Translation DT2851) and processed using Media Cybernetics Image-Pro Plus software. Various locations in the hologram reconstruction were observed by traversing the hologram in two directions, and the video camera of the image display in the third direction. Positions were selected for viewing using stepping motor-driven linear traversing systems (Velmex, Model VP9000) having $1000 \mathrm{~nm}$ positioning accuracies. The combined holocamera/reconstruction system allowed objects as small as $3000 \mathrm{~nm}$ to be seen and the size of objects as small as $0.01 \mathrm{~mm}$ to be measured with $10 \%$ accuracy. The reconstruction system was also used to measure flow properties from shadowgraph photographs with the photographs placed in the hologram holder whch allowed for two-dimensional traversing as before.

Drop sizes and velocities were measured as described by Hsiang and coworkers [17-20] whereas ligament and liquid surface properties were found similar to Sallam et al. [23]. Drops generally were spherical and could be represented by an average diameter. Experimental uncertainties for drop diameters larger than $0.01 \mathrm{~mm}$ are less than $10 \%$, increasing inversely to the drop diameter for smaller sized drops. Drop velocities were found from simple arithmetic averages (because drop velocity distributions were nearly uniform) with experimental uncertainties (95\% confidence) less than 10\%). 


\section{$\underline{\text { Test Conditions }}$}

Test conditions are summarized in Table 1. Liquid properties summarized in Table 1 were measured as follows: liquid density using a set of hydrometers (Fisher model 11-582, 0.1\% accuracy), liquid viscosity using a Cannon-Fenske viscometer (Fisher model 13-617, 3\% accuracy) and surface tension using a ring tensiometer (Fisher model 20, 1\% accuracy). The present results for pure liquids agreed with the values appearing in Lange [24] within the accuracy of the instruments.

Test conditions were varied by considering three different liquids, liquid injector diameters of $0.5,1.0$ and $2.0 \mathrm{~mm}$, liquid jet velocities of $10-45 \mathrm{~m} / \mathrm{s}$ and air crossflow velocities of $35-142 \mathrm{~m} / \mathrm{s}$ at normal temperature and pressure. This yielded the following ranges of normalized test variables: liquidgas density ratios, $\rho_{\mathrm{L}} / \rho_{\mathrm{G}}=683-1021$; liquidgas viscosity ratios, $\mu_{\mathrm{L}} / \mu_{\mathrm{G}}=0.48-2.02$; jet exit diameters, $\mathrm{d}=0.5,1.0$ and $2.0 \mathrm{~mm}$; ratio of crossflow drag-to-surface-tension forces, characterized by the Weber number, of $\mathrm{We}=$ 30-260; liquid/gas momentum flux ratios, $q=3-200$; and the ratio of liquid-viscouslsurface-tensionforces, characterized by the jet Ohnesorge number, of $\mathrm{Oh}=$ 0.003-0.12. Crossflow Mach numbers were less than 0.10 ; therefore, effects of compressibility were small.

\section{RESULTS AND DISCUSSION}

\section{Flow Visualization}

The presentation of the experimental results will begin with pulsed shadowgraph photography in order to provide visualizations of the flows at various nonturbulent round liquid jet test conditions. The properties of the liquid jets for various crossflow conditions are illustrated in Fig. 2. These test conditions involved a water jet having an injector exit diameter of $1 \mathrm{~mm}$ for various crossflows represented by the crossflow Weber number, We, however, these results are typical of the present observations at other test conditions as weil as the earlier observations of Mazallon et al. [1]. The leftmost image of the liquid jet, for $\mathrm{We}=0$, exhibits a smooth liquid surface with no disturbances or protrusions of the surface of liquid column, and no initiation of atomization, even though the jet Reynolds number at this condition is relatively large, $\operatorname{Re}=30,000$. This behavior is similar to past observations of atomization using injectors of the present design $[15,16]$. All liquid jet operating conditions considered during the present investigation had similar smooth liquid surfaces with no significant deformation, or variation of the crosstream diameter or initiation of atomization, over the length of the jet, when no crossflow was present; therefore, all the liquid jets referred to in the following have this same characteristic in the absence of crossflow. These results also provide direct proof that all primary breakup processes observed during the present investigation were caused by air crossflow rather than by liquid vorticity or liquid turbulence, which is responsible for other liquid jet breakup processes such as turbulent primary breakup [16].

For present conditions where effects of liquid viscosity were small $(\mathrm{Oh} \leq 0.4)$, three regimes of primary breakup of the liquid jet were observed for fixed liquid jet conditions as the crossflow velocity (characterized by the Weber number) was increased, as follows: bag breakup, multimode (or bag/shear) breakup, and shear breakup, as illustrated in the three rightmost shadowgraphs appearing in Fig. 2. At the smallest velocities, not illustrated in Fig. 2, the liquid column was deformed to a slight degree and deflected downstream, with no breakup at the liquid surface over the range of jet lengths that could be observed over the present test range. For all crossflow conditions observed thus far, however, this flow regime eventually leads to breakup of the liquid column as a whole if observations can be extended for a sufficiently large jet length, see Mazallon et al. [1] for a visualization of this regime as well as discussion of earlier observations within the liquid column breakup regime.

As the crossflow velocities increase, the next primary breakup regime that is observed is the bag breakup regime. $\boldsymbol{A n}$ illustration of bag breakup appears in Fig. 2 for $\mathrm{We}=8$. In this case the liquid column at first deforms in a direction normal to the crossflow, to yield an ellipsoidal crossection. This behavior is caused by reduced gas pressures along the sides of the liquid jet due to acceleration of the gas across the liquid column, with the lateral motion eventually stabilized by surface tension, somewhat analogous to the behavior of individual drops subjected to shock wave disturbances in the deformation regime [17-22]. The increased drag forces due to the flattened shape of the liquid column enhances its tendency to be deflected downstream due to the crossflowing gas motion. Once a significant degree of flattening is present, somewhat thickened regions appear between the nodes which are very similar to the baglike structures appearing at the center of deformed drops in the bag breakup regime observed during the secondary breakup of drops $[17,18,19]$. This behavior involves the formation of 
bags as a result of the deformation of the central portion of the liquid column downstream due to the higher pressure of the stagnating gas flow on the upstream side of the liquid column. With increasing distance along the liquid column, the bags progressively grow in the downstream direction and thus as they approach their maximum size they begin to progressively break up, beginning at the tip, in a mechanism very similar to secondary bag breakup regime of drops subjected to shock wave disturbances [21]. This is followed by breakup of the connecting liquid columns that subsequently divide into relatively large drops, once again similar to the secondary bag breakup regime of drops subjected to shock wave disturbances [21]. This behavior tends to separate drops according to size along the liquid column, with the smallest drops associated with breakup of the bag appearing first followed by large drops associated with breakup of the connecting liquid columns between the nodes. Similar bag breakup regimes have been observed for nonturbulent round liquid jets in crossflow by Mazallon et al. [1], Wu et al. [2] and references cited therein.

Shifting to conditions at the largest crossflow velocities considered during the present investigation, or at the largest Weber numbers, liquid primary jet breakup enters the shear breakup regime. An illustration of shear breakup appears in the rightmost photograph of Fig. 2, for $\mathrm{We}=220$. Similar to bag breakup, the shear breakup process begins by deflection of the liquid column in the streamwise direction of the crossflow, but with negligible distortion of the liquid column. Wavelike disturbances appear on the upstream side of the deflected liquid column, probably as a result of Rayleigh/Taylor instability (i.e., as a result of acceleration of a fluid of greater density toward a fluid of lesser density). The wavelengths of these disturbances are smaller than the diameter of the liquid column, however, and they do not develop into the nodes observed in the bag-breakup regime. Instead, they grow into ligaments that form around the periphery of the liquid jet and extend from the downstream side of the liquid column. These ligaments are terminated when drops are stripped from their ends, very similar to the secondary breakup of drops in the shear breakup regime when drops are subjected to shock wave disturbances [17-20]. With increasing distance along the liquid column, the wavelength of these disturbances tends to increase, resulting in progressively increasing diameters of both ligaments, and the drops forming at the end of the ligaments, with increasing distance along the liquid surface. This behavior is somewhat analogous to the progressive increase in the size of ligaments and the drops formed from them, as a function of time in the shear breakup regime of the secondary breakup of drops subjected to shock wave disturbances.

Finally, there is a range of crossflow velocities between those yielding bag breakup and those yielding shear breakup that results in a complex mixture of the properties of these two boundary regimes, called the multimode (or bag/shear) breakup regime [1]. An illustration of multimode breakup appears between the bag and shear breakup regime photographs in Fig. 2, for $\mathrm{We}=30$. In this case, both widely spaced nodes appear and result in the formation of bags, as well as closely spaced ligaments leading to the formation of drops, analogous to the multimode regime observed for the secondary breakup of drops subjected to shock wave disturbances [17-19,21].

\section{Primary Breakup Regimes}

Exploiting the similarities between the primary breakup regimes of nonturbulent round liquid jets (denoted "liquid jets" in the following) in crossflow and the secondary breakup of drops, the breakup regimes of liquid jets in crossflow were correlated in terms of the Weber and Ohnesorge numbers, as first proposed by Hinze [25] for the secondary breakup of drops exposed to shock wave disturbances and used subsequently by most investigators of secondary drop breakup, see Refs. 17-22 and references cited therein. The resulting breakup regime map is plotted in Fig. 3. In this figure, the present regime boundaries are located where roughly half the observations corresponded to conditions similar to the two boundary regimes, similar to past work for the primary breakup of liquid jets in crossflow [1] and the secondary breakup of drops subjected to shock wave disturbances [19]. Experimental uncertainties (95\% confidence) of these boundaries are less than $25 \%$ for We and are less than $5 \%$ for Oh (which has a negligible effect for the test range of Fig. 3 in any event), defined largely by problems of identifying particular breakup behaviors in a consistent way. Also shown on the figure are the earlier determinations of breakup regime boundaries of round nonturbulent liquid jets in crossflow due to Mazallon et al. [1] and for the secondary breakup of drops subjected to shock wave disturbances due to Hsiang and Faeth [19].

As mentioned earlier, the three breakup regime boundaries of round nonturbulent liquid jets in crossflow - for onset of bag, multimode and shear 
breakup - are somewhat analogous to the secondary breakup regime boundaries of drops subjected to shock wave disturbances. The main difference between liquid column and drop breakup is that secondary drop breakup responds to a greater degree to increasing $\mathrm{Oh}$ than liquid jet breakup, with progressively increasing We with increasing $\mathrm{Oh}$ at the transitions to various breakup regimes for $\mathrm{Oh}>0.01$. At small $\mathrm{Oh}<0.01$, however, the transitions for both liquid column breakup and the secondary breakup of drops are essentially independent of Oh. In this regime the transition to shear breakup for liquid jets in crossflow at $\mathrm{We}=110$ is identical for the results of Mazallon et al. [1] and the present investigation. The present transition to multimode breakup for liquid jets in crossflow at $\mathrm{We}=\mathbf{3 0}$, however, occurs sooner than the results of Mazallon et al. [1] at $\mathrm{We}=60$; this difference is felt to be due to somewhat different definitions for the onset of this regime which is subjective and rather difficult to define compared to the other transitions illustrated in Fig. 2. Unfortunately, the present shock tube apparatus could not be operated reliably at the low crossflow velocities needed to observe the bag breakup transition observed by Mazallon et al. [1] at $\mathrm{We}=5$. Finally, effects of the liquid jet/crossflow momentum ratio, $\mathbf{q}=\rho_{\mathrm{L}} \mathbf{v}_{\mathrm{j}}{ }^{2} /\left(\rho_{\mathrm{G}} \mathbf{u}_{\infty}{ }^{2}\right)$, on breakup regime transitions were negligible for present test conditions which involved $q=3-200$; this behavior confirms the earlier finding of negligible effects of $q$ on breakup regime transitions due to Mazallon et al. [1] over the somewhat broader range, $\mathrm{q}=100-8000$. In fact, increasing jet velocities simply stretched out the breakup process in the coordinate y aligned with the jet exit velocity with little other effect except modification of drop velocities after breakup in the $y$ direction, as quantified later.

\section{Onset of Breakup}

A feature of liquid jet breakup on crossflows for some conditions is that similar to the secondary breakup of drops subject to shock wave disturbances there is relative universality of liquid column deformation at the onset of breakup. This behavior is illustrated in Fig. 4, where $d_{j} / d_{i}$, the ratio of the initial jet diameter to the minimum (streamwise) length of the liquid column at the onset of drop formation along the liquid surface (as illustrated in the inset sketch of Fig. 4), is plotted as a function of $\mathrm{We}$ for $\mathrm{We}>0$, i.e., for conditions exceeding the $\mathrm{We}$ required for the onset of breakup. Measurements shown on the plot include results from Mazallon et al. [1] (noting that $\mathrm{d}_{\mathrm{j}} / \mathrm{d}_{\mathrm{i}} \approx \mathrm{d}_{\mathrm{f}} / \mathrm{d}_{\mathrm{j}}$, where $\mathrm{d}_{\mathrm{f}}$ is the frontal dimension of the jet at the onset of drop formation along the liquid jet, when the crossectional area of the jet is preserved during deformation as established by Mazallon et al. [1]). The various breakup regime boundaries are also shown on the plot, taking $\mathrm{We}=5$ at the onset of bag breakup from Mazallon et al. [1] and $\mathrm{We}=30$ and 110 at the onset of the multimode and shear breakup regimes from the present investigation. For breakup in the bag breakup regime, $\mathrm{d}_{\mathrm{j}} / \mathrm{d}_{\mathrm{i}} \approx 2$ independent of the value of We, which is in excellent agreement with the value found for onset of breakup for drops subjected to shock wave disturbances for all We studied after the onset of breakup [17,18,19]. In contrast to this behavior, however, values of $\mathrm{d}_{j} / \mathbf{d}_{\mathrm{i}}$ for breakup of round liquid jets in crossflow subsequently decrease in the multimode regime before reaching a constant value of $d_{j} / d_{i} \approx 1$, i.e., no significant deformation prior to the onset of breakup, in the shear breakup regime. This difference in behavior is observed for the relatively wide range of liquid jet velocities (or values of q) that were considered during the present investigation. The difference of behavior between the primary breakup of round liquid jets in crossflow and the secondary breakup of drops appears to be caused by the fact that the liquid jets are provided with a continuous source of liquid having a relatively large liquid momentum along the axis of the jet, rather than the fixed inertia of a single liquid drop.

Another difference between liquid jet breakup in crossflow and the secondary breakup of drops subjected to shock wave disturbances involves the time of onset of breakup (which is readily found by measuring the distance along the axis of the jet from its exit to the point where drops are just formed, $y_{i}$, and neglecting variations of the velocity of the jet along its axis (which present measurements showed to be small), to obtain, $\left.t_{i}=y_{i} / v_{j}\right)$. For the secondary breakup of drops subjected to shock wave disturbances, the time of onset of breakup, normalized by the characteristic secondary drop breakup time of Ranger and Nicholls [26], is $t_{i} / t^{*} \approx 2$ for We ranging over the bag, multimode and shear breakup regimes $[20,21,22]$. This behavior can be rationalized by noting that the characteristic liquid phase velocity, based on conservation of momentum principles, is $u_{\mathrm{L}}=\left(\rho_{\infty} / \rho_{\mathrm{L}}\right)^{1 / 2} \mathrm{u}_{\infty}$ whereas it is reasonable to assume that liquid motion must cause deformation of the drop involving a fixed fraction of the initial drop diameter at the time of onset of breakup (because $d_{j} / d_{j}$ is a constant for drop breakup for a wide range of $\mathrm{We}$ ). Then assuming that the time required to reach the onset of breakup is proportional to the time required to move a distance equal to the 
drop diameter, at the characteristic liquid phase velocity, implies that $t_{i}-t^{*}=d_{j}\left(\rho_{L} / \rho_{\infty}\right)^{1 / 2} / u_{\infty}$ or $t_{i} / t^{*}=$ constant $\approx 2$ as observed for the secondary breakup of drops.

Based on the previous discussion, it is plausible that $\mathrm{t}_{\mathrm{i}} / \mathrm{t}^{*}$ should also be a constant at small We for liquid column breakup in a crossflow where the results of Fig. 4 suggest similar levels of deformation at the onset of breakup for liquid columns in crossflow and drops subjected to shock wave disturbances. This idea is evaluated in Fig. 5, where $t_{i}$ at the onset of breakup of liquid jets in crossflow is found as just described in the previous paragraph. Measurements shown on this plot include the earlier measurements and their correlation from Mazallon et al. [1], the present measurements, and the correlation of results for the secondary breakup of drops subjected to shock wave disturbances, $t_{\mathrm{i}} / \mathrm{t}^{*}=\mathbf{2}$, from Dai et al. [22]. Finally, the breakup regime transitions, found as discussed in connection with Fig. 4, are also shown on the plot for reference purposes. As anticipated, the onset of breakup for liquid columns in crossflow approximates $\mathrm{t}_{i} / \mathrm{t}^{*}=\mathbf{2}$ for small We associated with bag breakup, where results illustrated in Fig. 4 show that liquid column deformation at the time of onset of breakup is similar to past observations for drops. At higher We, where there is little deformation of the liquid column prior to onset of breakup, however, the mechanism must change and $t_{i} / t^{*}$ progressively decreases with increasing We. In this region, present results are in good agreement with the earlier findings of Mazallon et al. [13, yielding the following correlation:

$$
t_{i} / t^{*}=8.2 \mathrm{We}^{-1 / 2}, \quad \mathbf{1 0} \leq \mathrm{We} \leq 2000
$$

with a correlation coefficient of the fit of 0.95 . There was little effect of either Oh or q on these results over the present test range so that the Weber number mainly influences $t_{i} / t^{*}$ for the conditions considered during Mazallon et al. [1] and the present investigation. The reasons for the difference in the behavior of the time of onset of breakup of liquid jets in crossflow and the secondary breakup of drops, however, are currently not known.

\section{Liquid Surface Waves}

Another feature of liquid jet breakup in crossflow is the appearance of waves along the surface of the liquid column. Mazallon et al. [1] observed two kinds of waves, as follows: (1) waves having long wavelengths between nodes at Weber numbers near the onset of bag breakup that were associated with the formation of the bags observed during bag breakup illustrated in Fig. 2, and (2) waves having smaller wavelengths at large Weber numbers that were associated with periodic disturbances of liquid stripping along the sides of the liquid column during shear breakup that were mentioned in connection with shear breakup illustrated in Fig. 2. Unfortunately, the small Weber number conditions needed to explore the long wavelength regime could not be reached reliably using the present shock tube apparatus; therefore, the following discussion will be limited to the small wavelength regime associated with shear breakup.

The wavelength, $\lambda_{\mathrm{s}}$, of the small wavelength disturbances along the surface liquid jets in crossflow were best observed on the upstream side of the liquid column as sketched in the inset figure of Fig. 6. The wavelengths, measured as indicated in the inset figure, are plotted as a function of the Weber number in Fig. 6. Results shown in this figure include the measurements of Mazallon et al. [1] and their conelation, and the present measurements. The experimental uncertainties (95\% confidence) of the wavelengths illustrated in Fig. $\mathbf{6}$ are estimated to be smaller than $25 \%$, largely due to wavelength irregularities similar to those seen in Fig. 2.1 Finally, the breakup regime transitions, found as discussed in connection with Fig. 4, are also shown on the plot for reference purposes. The present measurements and those of Mazallon et al. [1] agree well within experimental uncertainties. In general, the surface wavelengths are smaller than the liquid column wavelengths observed by Mazallon et al. [ 13 with the liquid column waves associated with bag and the early stages of multimode breakup and the smaller liquid surface waves associated with ligament and drop formation during shear breakup. Thus, $\lambda_{c} / d_{j}>1$ whereas $\lambda_{\mathrm{s}} / \mathrm{d}_{\mathrm{j}}<1$ with both types of waves having progressively smaller wavelengths as the Weber number increases. The latter waves are present on the upstream side of the liquid column and appear to be initiated by Rayleigh/Taylor instability resulting from the acceleration of a fluid of greater density toward a fluid of lesser density. Finally, the best-fit correlation of the measurements was achieved as a function of the Weber number alone, and can be expressed as follows:

$$
\lambda_{s} / \mathrm{d}_{\mathrm{j}}=2.80 \mathrm{We}^{-1 / 2}, \quad \mathrm{We}>10
$$

where the correlation coefficient of this fit is $\mathbf{0 . 8 2}$. 


\section{Drop Velocity Properties}

Drop velocities after breakup were measured using double-pulse shadowgraphy, in regions where the dispersed flow region was dilute, and doublepulse holography, in regions where the dispersed flow region was dense. The resulting distributions of drop velocities directed along the initial direction of the liquid jet, $v_{p}$, and directed along the initial direction of the crossflow, $u_{p}$, are illustrated in Fig. 7. First of all, it is seen that both components of the drop velocity are uniform, i.e., independent of drop diameter. $\boldsymbol{A n}$ apparent exception to this behavior involves small drops with $\mathrm{d}_{\mathrm{p}} / \mathrm{SMD}<0.5$, however, this behavior is felt to be an artifact of the relatively faster relaxation times of small drops compared to large drops. The normalizations were chosen to compare the $v_{p}$ velocity component with the jet exit velocity, $v_{p} / v_{j}$, and the $u_{p}$ velocity component with the characteristic liquid velocity component defined earlier, e.g., $u_{L}=u_{\infty}\left(\rho_{G} / \rho_{L}\right)^{1 / 2}$ or $u_{p} / u_{L}$. The resulting velocity correlations from Fig. 7 are as follows:

$$
\begin{gathered}
\mathrm{v}_{\mathrm{p}} / \mathrm{v}_{\mathrm{j}}=0.7 \\
\mathrm{u}_{\mathrm{p}} / \mathrm{u}_{\mathrm{L}}=\mathrm{u}_{\mathrm{p}}\left(\rho_{\mathrm{L}} / \rho_{\mathrm{G}}\right)^{1 / 2} / \mathrm{u}_{\mathrm{o}}=6.4
\end{gathered}
$$

where the uncertainties (95\% confidence) of the constants on the right-hand sides (RHS) of these expressions are comparable to the uncertainties of the measurements of the velocity measurements themselves (95\% confidence) or $10 \%$. Measurements of both velocity components indicate some effect of the drag of the crossflowing gas during the breakup process on the velocities of the drops after breakup. These effects tend to reduce the $v_{p}$ component from $v_{j}$ to some extent and to increase the $u_{p}$ component significantly from $u_{\mathrm{L}}$.

\section{Ligament and Drop Sizes Along the Liquid $\underline{\text { Surface }}$}

In order to consider ligament and drop sizes along the liquid surface, it is necessary to relate the time that the liquid was in the liquid jet flow and the distance from the jet exit in the initial direction of the jet velocity, y. In the present case, assuming that the velocity of the liquid jet in the y direction remains constant (which is correct for present conditions as noted earlier), the distance from the jet exit can be related to the time required for the flow to reach this position, as follows:

$$
\mathrm{y}=\mathrm{Vt}
$$

Then sampling ligament and drop properties at various distances from the jet exit in the y direction provided a way to assess the temporal development of the liquid breakup process.

A second general approximation used to treat ligament and drop properties along the liquid surface involved assuming that ligaments and drops formed at various times after injection can be treated in an analogous way to the properties of ligaments and drops formed during secondary breakup of drops at various times after the start of the breakup process. This approximation was justified for two reasons, as follows: the general relationship between the breakup regimes of liquid jets in crossflow and the secondary breakup of drops seen in Fig. 3, and relatively small variation of the jet velocities in the y direction with increasing distance from the jet exit, which implies relatively little interaction between packets of jet liquid at various distances from the jet exit.

The first breakup property considered with respect to ligament and drop sizes along the liquid surface was their size at the onset of ligament and drop formation. Approximate analysis to find these properties was used to help interpret and correlate the measurements analogous to the approach used to analyze these properties during turbulent primary breakup at the surface of turbulent liquid jets in still air [27]. In particular, ligament diameters at the onset of ligament formation were found by equating the crosstream momentum of the liquid near the surface of the liquid column to the maximum surface tension force experienced during the formation of a ligament; at this condition, the ligament consists of a hemisphere having a diameter $d_{\ell i}$. Assuming that the characteristic liquid phase crosstream velocity, $\mathrm{u}_{\mathrm{L}}$, provides a reasonable measure of the momentum in the crosstream direction per unit mass of liquid near the liquid surface, yields the following expression for the force balance along the axis of the ligament at the critical surface tension condition:

$$
\rho_{\mathrm{L}} \mathrm{u}_{\mathrm{L}}^{2} \mathrm{~d}_{\ell \mathrm{i}}{ }^{2} \sim \sigma \mathrm{d}_{\ell \mathrm{i}}
$$

Then substituting the expression for $\mathrm{u}_{\mathrm{L}}$ into Eq. (6) and simplifying, yields:

$$
\mathrm{d}_{e \mathrm{i}} / \mathrm{d}_{\mathrm{j}}=\mathrm{C}_{f \mathrm{i}} / \mathrm{We}
$$

where $\mathrm{C}_{\ell \mathrm{i}}$ is an empirical constant that should have a value on the order of unity. Next, drop formation mainly occurred at the tips of ligaments. Based on past observations of drop formation from ligaments 
protruding from the liquid surfaces [27], it seems likely that the ligament breakup mechanism involves Rayleigh breakup at the tip of the ligaments so that drop diameters at the onset of drop formation should be proportional to ligament diameters at the onset of ligament formation. The condition can be formulated as follows:

$$
\mathrm{d}_{\mathbf{p} \mathbf{i}} / \mathrm{d}_{\ell \mathrm{i}}=\mathrm{C}_{\mathbf{p i}}
$$

where $\mathrm{C}_{\mathrm{pi}}$ is an empirical constant having a value on the order of unity.

Present measurements of ligament diameters at the onset of ligament formation and drop diameters at the onset of drop formation are plotted as a function of the Weber number, as suggested by Eqs. (7) and (8), in Fig. 8. The various breakup regime boundaries, found as noted earlier, are also plotted in Fig. 8 for reference purposes. The scatter of the measurements is within the scatter anticipated based on experimental uncertainties with the exception of $\mathbf{d}_{f^{i}} / \mathbf{d}_{j}$ near the bag breakup regime where the mechanism of breakup clearly differs from the mechanism considered during the development of Eq.

(7). The power of We for the correlation of $d_{\ell} / d_{j}$ is not -1 as suggested by Eq. (7), however, and can be represented better by the following empirical fit that is shown on the plot:

$$
\mathrm{d}_{\ell} / \mathrm{d}_{\mathrm{j}}=0.54 / \mathrm{We}^{1 / 2}
$$

where the two data points near the bag breakup regime in Fig. 8 have been ignored when developing Eq. (9). The standard deviation of the coefficient of Eq. (9) is $13 \%$, the empirical power of We is not statistically different from $-1 / 2$ and the correlation coefficient of the fit is 0.92 . The reduction of the power of We in Eq. (9) from -1 to $-1 / 2$ is statistically significant but is not large in view of the approximations used to find Eq. (7). Finally, the coefficient appearing in Eq. (9) is on the order of unity as expected.

The correlation of $d_{p i} / d_{\ell \mathrm{i}}$ plotted in Fig. 8 was measured by finding drops where drop formation had just occurred at the tip of a ligament, measuring $\mathrm{d}_{\mathrm{p} i} / \mathrm{d}_{\ell \mathrm{i}}$ for each condition of this type and averaging these ratios over all the measurements to obtain an experimental uncertainty (95\% confidence) less than $10 \%$. The results indicated that $\mathrm{d}_{\mathrm{p} i} / \mathrm{d}_{\ell \mathrm{i}}$ is a constant over the present test range, as follows:

$$
\mathrm{d}_{\mathrm{pi}} / \mathrm{d}_{\ell \mathrm{i}}=1.2
$$

where the standard deviation of $\mathrm{C}_{\mathrm{pi}}$ is $5 \%$. As anticipated from Eq. (8), the value of $d_{p i} / d_{\ell \mathrm{i}}$ is independent of We and is on the order of unity. For classical Rayleigh breakup [28], the value of $\mathrm{C}_{\mathrm{pj}}$ might be expected to be larger than the value in Eq. (10), nearer to 2. Smaller values were observed for present conditions, however, due to the formation of satellite drops in some instances. Another reason for this behavior could also be the strain of the ligaments in the crosstream direction due to the crossflow, as suggested by the acceleration of the drops after breakup significantly above the characteristic liquid velocity noted in connection with Fig. 7.

The next breakup property that was considered involved the variation of ligament and drop sizes as a function of distance from the jet exit during primary breakup of liquid jets in crossflow. These properties were analyzed using methods analogous to those used by Chou et al. [20] when considering the temporal development of the breakup process during the secondary breakup of drops subjected to shock wave disturbances in the shear breakup regime. This involved considering each element of fluid in the liquid jet, having the crossection of the jet, to act analogous to drops having a similar diameter, but unaffected by the adjacent liquid elements, as it convects away from the jet exit, with the time of development of the breakup process related to the distance from the jet exit in the direction using Eq. (5). Similar to Chou et al. [20] for the shear breakup of drops, the present approach was motivated by flow visualizations of primary breakup of liquid jets in crossflow similar to the behavior illustrated in Fig. 2. These visualizations showed that ligaments (which subsequently form drops from their tips by a process that appears to be similar to Rayleigh breakup of a liquid jet) are stripped from the periphery of the liquid column from a vortical region (or a viscous boundary-layer-like flow) near the surface of the jet on the upstream (windward) side of the liquid column during primary breakup in the shear breakup regime. Similar to the temporal evolution of the secondary breakup of drops subjected to shock wave disturbances in the shear breakup regime [20], two basic types of behavior were observed during the present experiments, as follows: (1) a regime where there was a progressive increase of ligament diameters with increasing distance from the jet exit in the y direction, along with a corresponding increase of the diameters of drops formed from these ligaments (which was largely seen when the ligament viscosity and the 
distance y were both small) and (2) a regime where the ligament diameters, and the diameters of drops formed at the tips of the ligaments, were relatively independent of distance from the jet exit in the $y$ direction (which was largely seen when the liquid viscosity and the distance y were both large). For such conditions, the liquid viscosity had an important effect on ligament, and thus drop, sizes after breakup, even though all test conditions involved sufficiently small Ohnesorge numbers so that variations of liquid viscosity did not affect the criteria for various breakup regime transitions. Then, associating the diameter of the ligaments with the thickness of the viscous shear layer in the liquid jet caused by the crossflow, and proceeding in the same manner as Chou et al. [20], the average ligament diameter is given as follows for the two different ligament formation regimes:

$$
\begin{gathered}
d_{\ell} / d_{j}=C_{y}\left(v_{L} y /\left(v_{j} d_{j}^{2}\right)\right)^{1 / 2}, \quad y / y_{c}<1 \\
d_{\ell} / d_{j}=C_{c}, \quad y / y_{c}>1
\end{gathered}
$$

where Eq. (5) has been used to relate the time of development of the ligament formation process to the distance, $y$, from the jet exit. The empirical parameters, $\mathrm{C}_{\mathrm{y}}$ and $\mathrm{C}_{\mathrm{c}}$, are expected to be constants having values on the order of unity. Finally, the condition $\mathrm{y}=\mathrm{y}_{\mathrm{c}}$ denotes when the process makes the transition from conditions where ligament diameters progressively increase with increasing $y$, to conditions where ligament diameters become independent of the distance y. Finally, based on considerations similar to those for the onset of ligament and drop formation, the ligament breakup mechanism was assumed to involve Rayleigh breakup so that drop diameters after ligament breakup should be proportional to the ligament diameter, similar to the considerations leading to Eq. (8) at the onset of drop breakup. Then the expression for drop diameters after breakup as a function of distance from the jet exit becomes:

$$
\mathrm{d}_{\mathrm{p}} / \mathrm{d}_{\ell}=\mathrm{C},
$$

Present measurements of ligament diameter, and the diameter of drops subsequently formed from the ligaments, are plotted as a function of the liquid viscosity parameter as suggested by Eqs. (11)-(13) in Fig. 9. The scatter of the measurements is generally within experimental uncertainties, with the somewhat larger scatter at large values of the viscosity parameter attributable to greater difficulties resolving the sizes of ligaments and drops in the very dense sprays near the liquid surface at these conditions, see the shear breakup photograph in Fig. 2. The power of the viscosity parameter in the ligament diameter expression of Eq. (11) for $y / y_{c}<1$ is $1 / 2$ within statistical significance, in agreement with the simplified analysis. Then Eqs. (11) and (12) for ligament diameter properties yield best-fit values for the present measurements, as follows:

$$
\begin{gathered}
\mathrm{d}_{\ell} / \mathrm{d}_{\mathrm{j}}=2.8\left(v_{\mathrm{L}} \mathrm{y} /\left(\mathrm{v}_{\mathrm{j}} \mathrm{d}_{\mathrm{j}}^{2}\right)\right)^{1 / 2}, \mathrm{y} / \mathrm{y}_{\mathrm{c}} \leq 1 \\
\mathrm{~d}_{\ell} / \mathrm{d}_{\mathrm{j}}=0.11, \quad \mathrm{y} / \mathrm{y}_{\mathrm{c}}>1
\end{gathered}
$$

where the standard deviations of the coefficients appearing in Eqs. (14) and (15) are 0.15 and 0.20, respectively. Finally, the transition between the region where ligament diameters progressively increase with increasing distance from the jet exit and the region where ligament diameters become relatively independent of distance from the jet exit is given by a value of the viscosity parameter of 0.001 , which implies:

$$
\mathrm{y}_{\mathrm{c}} / \mathrm{d}_{\mathrm{j}}=0.001 /\left(\mathrm{v}_{\mathrm{L}} /\left(\mathrm{v}_{\mathrm{j}} \mathrm{d}_{\mathrm{j}}\right)\right)
$$

The correlation of $d_{p} / d_{\ell}$ plotted in Fig. 8 was found in the same manner at each point along the surface as was the case for onset of ligament and drop formation. This approach yields an experimental uncertainty (95\% confidence) of $d_{p} / d_{\ell}$ less than $15 \%$. The results indicate that $d_{p} / d_{\ell}$ is a constant for the present test range with the constant identical to the same ratio at the onset conditions of Eq. (10), or:

$$
\mathrm{d}_{\mathrm{p}} / \mathrm{d}_{\ell}=1.2
$$

with the standard deviation of $\mathrm{C}$, the same as $\mathrm{C}_{\mathrm{pi}}$ or $5 \%$. Finally, as anticipated from Eq. (13), the value of $\mathrm{d}_{\mathrm{p}} / \mathrm{d}_{\ell}$ is independent of the viscosity parameter and is on the order of unity. Other comments about $C_{p}$ are essentially identical to those made about $\mathrm{C}_{\mathrm{pi}}$ in connection with Eq. (10).

\section{Liquid Column Breakup}

The locations of the completion of the secondary breakup process in the direction of the liquid jet flow and the crossflow, $y_{b}$ and $x_{b}$, were analyzed similar to earlier treatment of nonturbulent liquid columns in crossflow due to $\mathrm{Wu}$ et al. [2] and turbulent liquid column breakup lengths due to Sallam et al. [23]. This was done by associating the time of penetration of liquid elements in the jet with the time of secondary breakup of drops due to shock 
wave disturbances. Adopting this approach, the time required for bag, multimode and shear breakup, $t_{b}$, is given by [1]:

$$
\left.t_{b}=C_{y b}\left(\rho_{L} / \rho_{G}\right)\right)^{1 / 2} d_{j} / u_{\infty}
$$

where $\mathrm{C}_{\mathbf{y b}}$ is an empirical parameter having a magnitude on the order of unity. Then the liquid column breakup distance in the y direction is $y_{b}=v_{j} t_{b}$ from Eq. (5) which yields the following expression for the normalized breakup length in the y direction:

$$
\mathrm{y}_{\mathrm{b}} / \mathrm{d}_{\mathrm{j}}=\mathrm{C}_{\mathrm{yb}} \mathrm{q}^{1 / 2}
$$

Note that this expression also implies from Eq. (18):

$$
t_{b} / t^{*}=C_{y b}
$$

Finally, proceeding in the same manner, it can be shown that the breakup length in the $\mathrm{x}$ direction is given by [2]:

$$
\mathrm{x}_{\mathrm{b}} / \mathrm{d}_{\mathrm{j}}=\mathrm{C}_{\mathrm{xb}}
$$

Measurements of $\mathrm{y}_{\mathrm{b}}$ and $\mathrm{x}_{\mathrm{b}}$ from $\mathrm{Wu}$ et al. [2] and the present investigation are illustrated in Fig. 10. Note the present measurements of $\mathrm{y}_{\mathrm{b}} / \mathrm{d}_{\mathrm{j}}$ are similar to those of $\mathrm{Wu}$ et al. [2] but somewhat smaller, yielding the correlation:

$$
\mathrm{y}_{\mathrm{b}} / \mathrm{d}_{\mathrm{j}}=2.6 \mathrm{q}^{1 / 2}
$$

where the actual best-fit value of the power of $\mathrm{q}, 0.49$ is not statistically different from the predicted value of $1 / 2$ from Eq. (19). Corresponding values of $\mathrm{C}_{\mathrm{yb}}$ from $\mathrm{Wu}$ et al. [2] are somewhat larger, $\mathrm{C}_{\mathrm{yb}}=3.02$ 4.49 , probably due to problems of precisely locating the end of the liquid column which is somewhat subjective and can differ from one individual to the next. In view of Eq. (20), present measurements then suggest:

$$
\mathrm{t}_{\mathrm{b}} / \mathrm{t}^{*}=2.6
$$

which is comparable but somewhat smaller than the value of $\mathrm{C}_{\mathrm{yb}}$ found from observation of secondary breakup of drops subjected to shock wave disturbances where $\mathrm{C}_{\mathrm{yb}}=6.0$ [22]. Finally, measurements of $x_{b} / d_{j}$ from both the Wu et al. [2] and the present investigation yield the rather surprising result:

$$
\mathrm{x}_{\mathrm{b}} / \mathrm{d}_{\mathrm{j}}=8.0
$$

for the total test range which involves q of 3-700 and We of 3-600, which is remarkably simple in view of the complexities of liquid column breakup in crossflow.

\section{CONCLUSIONS}

The formation of ligaments and drops, as well as the extent of the entire liquid column, was studied experimentally for liquid jets in air crossflows at normal temperature and pressure. Test conditions involved round nonturbulent water, ethyl alcohol and glycerol $(79 \%)$ jets injected normal to the crossflow for the following ranges of test variables (when combined with the earlier study of Mazallon et al. [1]): crossflow Weber numbers of $\mathrm{We}=0-2000$, liquidgas momentum ratios of $\mathrm{q}=100-8000$, liquidgas density ratios of $\rho_{\mathrm{L}} / \rho_{\mathrm{G}}=683-1021$, and Ohnesorge numbers of $\mathrm{Oh}=0.003-0.12$. The major conclusions of the study were as follows:

1. There is a useful general analogy between the primary surface breakup of nonturbulent round liquid jets in crossflow and the secondary breakup of drops subjected to shock wave disturbances which suggests modest streamwise interactions in the liquid jets, i.e., liquid breakup properties are not strongly affected by the liquidgas momentum ratio for values smaller than 8000 , the largest value considered during the present investigation.

2. Transitions to various breakup regimes are not influenced significantly by liquid viscosities for $\mathrm{Oh}<0.1$. Transition to multimode breakup occurred at $\mathrm{We}=30$ and to shear breakup at $\mathrm{We}$ = 110; present measurements could not reach the small Weber numbers at the onset of bag breakup, however, Mazallon et al. [1] find $\mathrm{We}=$ 5 for this transition.

3. Present measurements of the onset of liquid breakup of nonturbulent liquid jets in crossflow were in good agreement with the earlier measurements of Mazallon et al. [1] for the same flow configuration but yielded a normalized time of onset of breakup, $\mathrm{t}_{\mathrm{i}} / \mathrm{t}^{*}$ proportional to $\mathrm{We}^{-1 / 2}$ instead of being relatively independent of We similar to the onset of breakup for the secondary breakup of drops subjected to shock wave disturbances. This difference appears to be due to negligible deformation of the liquid column at the onset of breakup for large Weber numbers for liquid jets in crossflow as opposed to the secondary breakup of drops where substantial degrees of deformation always occur prior to breakup. 
4. Drop velocity distributions after breakup were relatively independent of drop size and approximated the liquid jet exit velocity, $v_{j}$, in the $y$ direction but were somewhat larger than the characteristic liquid phase velocity in the $\mathbf{x}$ direction, $\mathrm{u}_{\mathrm{L}}$, due to drag by the crossflowing gas on the drops as they formed.

5. Ligament diameters along the liquid surface were associated with the stripping of liquid from the vortical region (or viscous boundary-layer-like flow) in the liquid near its surface. This behavior resulted in progressive increases of ligament diameters with increasing distance in the $y$ direction for a time before the vortical layer reached a steady condition and ligament sizes became relatively independent of distance from the jet exit.

6. Corresponding diameters of drops caused by primary breakup along the liquid surface were comparable to the size of the ligaments and could be explained by assuming Rayleigh breakup caused drops to be formed from the end of ligaments.

7. Breakup of the liquid column as a whole in crossflow approximated total times of secondary breakup of drops subjected to shock wave disturbances yielding $y_{b} / d_{j}-q^{1 / 2}, t_{b} / t^{*}=2.6$ and $\mathrm{x}_{\mathrm{b}} / \mathrm{d}_{\mathrm{j}}=8.0$, with present results generally in good agreement with the earlier measurements of liquid column breakup in crossflow due to $\mathrm{Wu}$ et al. [2].

\section{ACKNOWLEDGMENTS}

Assistance from Richa Jolly and Diana Ma under the University of Michigan Undergraduate Research Opportunity Program is acknowledged. This research was sponsored by the Air Force Office of Scientific Research, Grant No. F49620-02-1-0007, under the technical management of J.M. Tishkoff. The U.S. Government is authorized to make copies of this article for governmental purposes notwithstanding any copyright notation thereon.

\section{REFERENCES}

[1] Mazallon, J., Dai, Z., and Faeth, G.M., "Primary Breakup of Nonturbulent Round Liquid Jets in Gas Crossflows," Atomization and Sprays, Vol. 9, No. 3, 1999, pp. 291-311.

[2] Wu, P.-K., Kirkendall, K.A., Fuller, R.F., and Nejad, A.S., "Breakup Processes of Liquid Jets in Subsonic Crossflows," Journal of Propulsion and Power, Vol. 13, No. 1, 1997, pp. 64-73.
[3] Geary, E.L., and Margettes, M.J., "Penetration of a High Velocity Gas Stream by a Water Jet," Journal of Spacecraft, Vol. 6, No. 1, 1969,pp. 79-81.

[4] Reichenbach, P.R., and Horn, K.P., "Investigation of Injectant Properties in Jet Penetration in a Supersonic Stream," AIAA Journal, Vol. 9, No. 3, 1971,pp. 469-471.

[5] Kush, E.A., and Schetz, J.A., "Liquid Jet Injection into a Supersonic Flow," AIAA Journal, Vol. 11,No. 9, 1979,pp. 1223-1224.

[6] Schetz, J.A., and Paddye, A., "Penetration of a Liquid Jet in Subsonic Airstreams,' AIAA Journal, Vol. 15, No. 10, 1977, pp. 1385 1390.

[7] Schetz, J.A., Kush, E.A., and Joshi, P.B., "Wave Phenomena in Liquid Jet Breakup in a Supersonic Crossflow," AIAA Journal, Vol. 15,1979, pp. 774-778.

[8] Nejad, A.S., and Schetz, J.A., "Effects of Properties and Location in the Plume on Droplet Diameter for Injection in a Supersonic Stream," AIAA Journal, Vol. 21, No. 7, 1983 , pp. 956-961.

[9] Nejad, A.S., and Schetz, J.A., "Effects of Viscosity and Surface Tension on a Jet Plume in Supersonic Cross-Flow,' AIAA Journal, Vol. 22, No. 4, 1984,pp. 458-459.

[10] Less, D.M., and Schetz, J.A., "Transient Behavior of Liquid Jets Injected Normal to a High-Velocity Gas Stream," AIAA Journal, Vol. 24, No. 12, 1986,pp. 1979-1985.

[11] Kitamura, Y., and Takahashi, T., "Stability of a Liquid Jet in Air Flow Normal to the Jet Axis," Journal of Chemical Engineering of Japan, Vol. 9, No. 4, 1976, pp. 282-286.

[12] Nguyen, T.T., and Karagozian, A.R., "Liquid Fuel Jet in a Subsonic Crossflow," Journal of Propulsion and Power, Vol. 8, No. 1, 1992, pp. 21-29.

[13] Karagozian, A.R., “An Analytical Model for the Vorticity Associated with a Transverse Jet," AIAA Journal, Vol. 24, 1986, pp. 429436.

[14] Higuera, F.J., and Martinez, M., "An Incompressible Jet in a Weak Crossflow," Journal of Fluid Mechanics, Vol. 249, 1993, pp. 73-97.

[15] Wu, P.-K., Miranda, R.F., and Faeth, G.M., "Effects of Initial Flow Conditions on Primary Breakup of Nonturbulent and Turbulent Round Liquid Jets." Atomization and Sprays, Vol. 5, 1995, pp. 175-196.

[16] Lienhard, J.H., "Velocity Coefficients for Free Jets from Sharp-Edged Orifices," Journal of 
Fluids Engineering, Vol. 106, 1984, pp. 1317.

[17] Hsiang, L.-P., and Faeth, G.M., "Near-Limit Drop Deformation and Secondary Breakup," International Journal of Multiphase Flow, Vol. 18,No. 5, 1992,pp. 635-652.

[18] Hsiang, L.-P., and Faeth, G.M., "Drop Properties After Secondary Breakup," International Journal of Multiphase Flow, Vol. 19,No. 5, 1993,pp. 721-735.

[19] Hsiang,L.-P., and Faeth, G.M., "Drop Deformation and Breakup Due to Shock Wave and Steady Disturbances," International Journal of Multiphase Flow, Vol. 21, No. 4, 1995,pp. 545-560.

[20] Chou, W.-H., Hsiang, L.-P., and Faeth, G.M. "Temporal Properties of Drop Breakup in the Shear Breakup Regime," International Journal of Multiphase Flow, Vol. 23, No. 4, 1997,pp. 657-669.

[21] Chou, W.-H., Faeth, G.M., "Temporal Properties of Secondary Drop Breakup in the Bag Breakup Regime," International Journal of Multiphase Flow, Vol. 24, No. 6, 1998, pp. 889-912.
[22] Dai, Z., and Faeth, G.M., "Temporal Properties of Secondary Breakup in the Multimode Breakup Regime," International Journal of Multiphase Flow, Vol. 27, No. 2, 2001, pp. 217-236.

[23] Sallam, K.A., Dai, Z., and Faeth, G.M., "Drop Formation at the Surface of Plane Turbulent Liquid Jets in Still Gases," International Journal of Multiphase Flow, Vol. 25, No. 6-7, 1999,pp. 1161-1180.

[24] Lange, N.A. Handbook of Chemistry, 8th ed., Handbook Publishers, Inc., Sandusky, Ohio, 1984,pp. 13-17.

[25] Hinze, J.O., "Fundamentals of the Hydrodynamic Mechanism of Splitting in Dispersion Processes," AIChE Journal, Vol. 1, No. 3, 1955,pp. 289-295.

[26] Ranger, A.A., and Nicholls, J.A., "The Aerodynamic Shattering of Liquid Drops," AIAA Journal, Vol. 7, No. 2, 1969, pp. 285. 290.

[27] Sallam, K.A., and Faeth, G.M., "Surface Properties During Primary Breakup of Turbulent Liquid Jets in Still Air,' AIAA Journal, in press.

Table 1. Summary of the test conditions."

\begin{tabular}{lrrr} 
Liquid & Water & Ethyl Alcohol & Glycerol (79\%) $^{\mathbf{b}}$ \\
\hline Density, $\mathrm{kg} / \mathrm{m}^{3}$ & 997 & 806 & 1205 \\
Liquid/gas density ratio, $\rho_{\mathrm{L}} / \rho_{\mathrm{G}}$ & 845 & 683 & 1021 \\
Viscosity, $\mathrm{kg} / \mathrm{ms} \times 10^{4}$ & 8.94 & 16.0 & 37.3 \\
Liquid/gas viscosity ratio, $\mu_{\mathrm{L}} / \mu_{\mathrm{G}}$ & 0.48 & 0.86 & 2.02 \\
Surface tension, $\mathrm{N} / \mathrm{m} \times 10^{-3}$ & 70.8 & 24.0 & 59.8 \\
Jet exit diameter, $\mathrm{mm}$ & $0.5,1.0,2.0$ & $1.0,2.0$ & 1.0 \\
Jet Weber number, We & $30-260$ & $30-260$ & $30-260$ \\
Liquidgas momentum ratio, q & $3-200$ & $20-100$ & $70-100$ \\
Jet Ohnesorge number, Oh & $3-5 \times 10^{-3}$ & $8-12 \times 10^{-2}$ & 0.12
\end{tabular}

\footnotetext{
${ }^{2}$ Air crossflow initially at $98.8 \mathrm{kPa}$ and $298 \pm 1 \mathrm{~K}$ in the driven section of the shock tube. Shock Mach numbers in the range 1.01-1.15. Properties of air were found at normal temperature and pressure: $\rho_{G}=1.18 \mathrm{~kg} / \mathrm{m}^{3}, \mu_{\mathrm{G}}=18.5 \mathrm{x}$ $10^{-2} \mathrm{~kg} / \mathrm{ms}$.

${ }^{\mathrm{b}}$ Percentage glycerin by mass in parenthesis.
} 

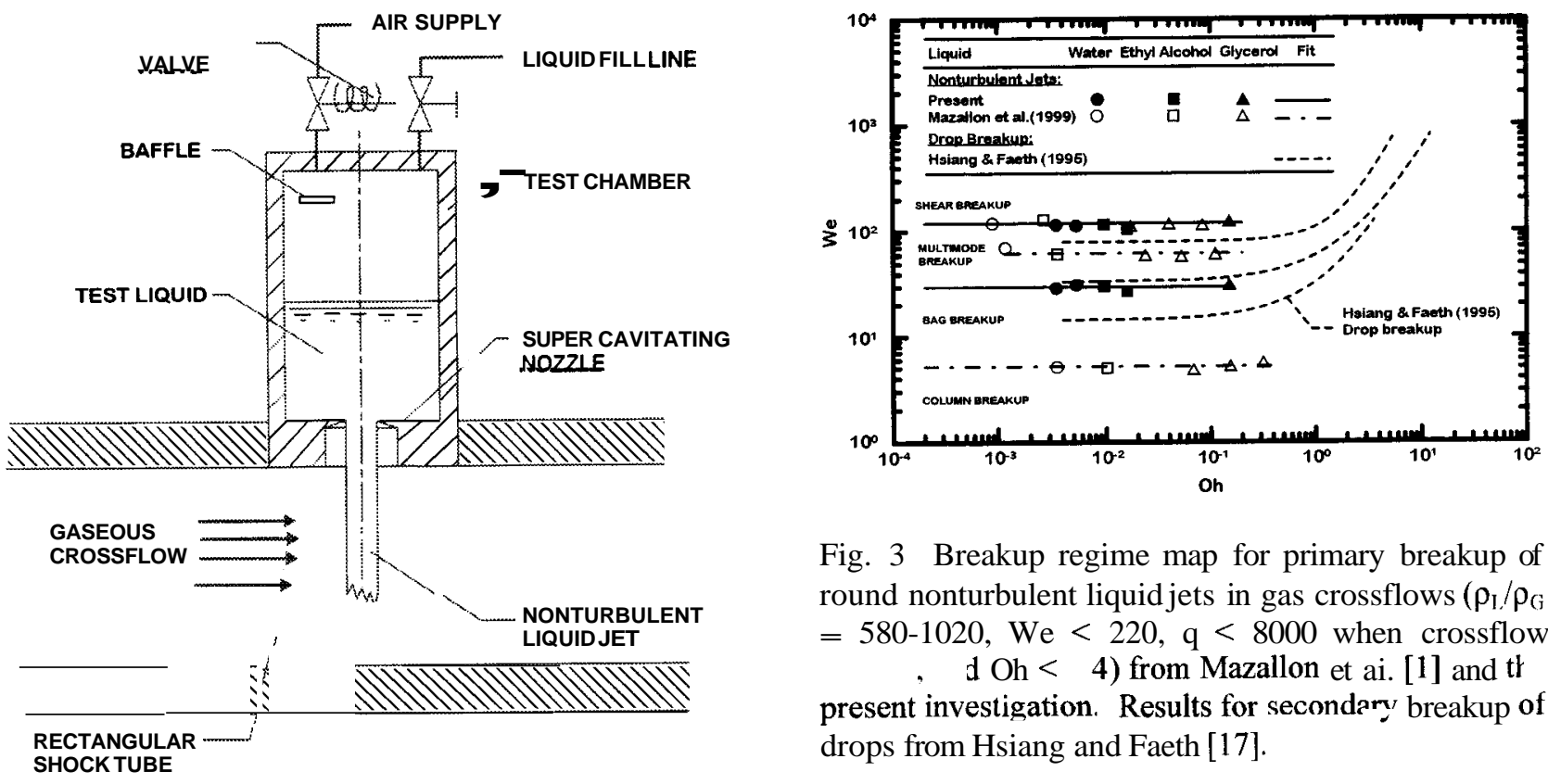

Fig. 3 Breakup regime map for primary breakup of round nonturbulent liquid jets in gas crossflows $\left(\rho_{\mathrm{I}} / \rho_{\mathrm{G}}\right.$ $=580-1020, \mathrm{We}<220, \mathrm{q}<8000$ when crossflow , d Oh < 4) from Mazallon et ai. [1] and th present investigation. Results for secondary breakup of drops from Hsiang and Faeth [17].

Fig. 1 Sketch of the test apparatus.
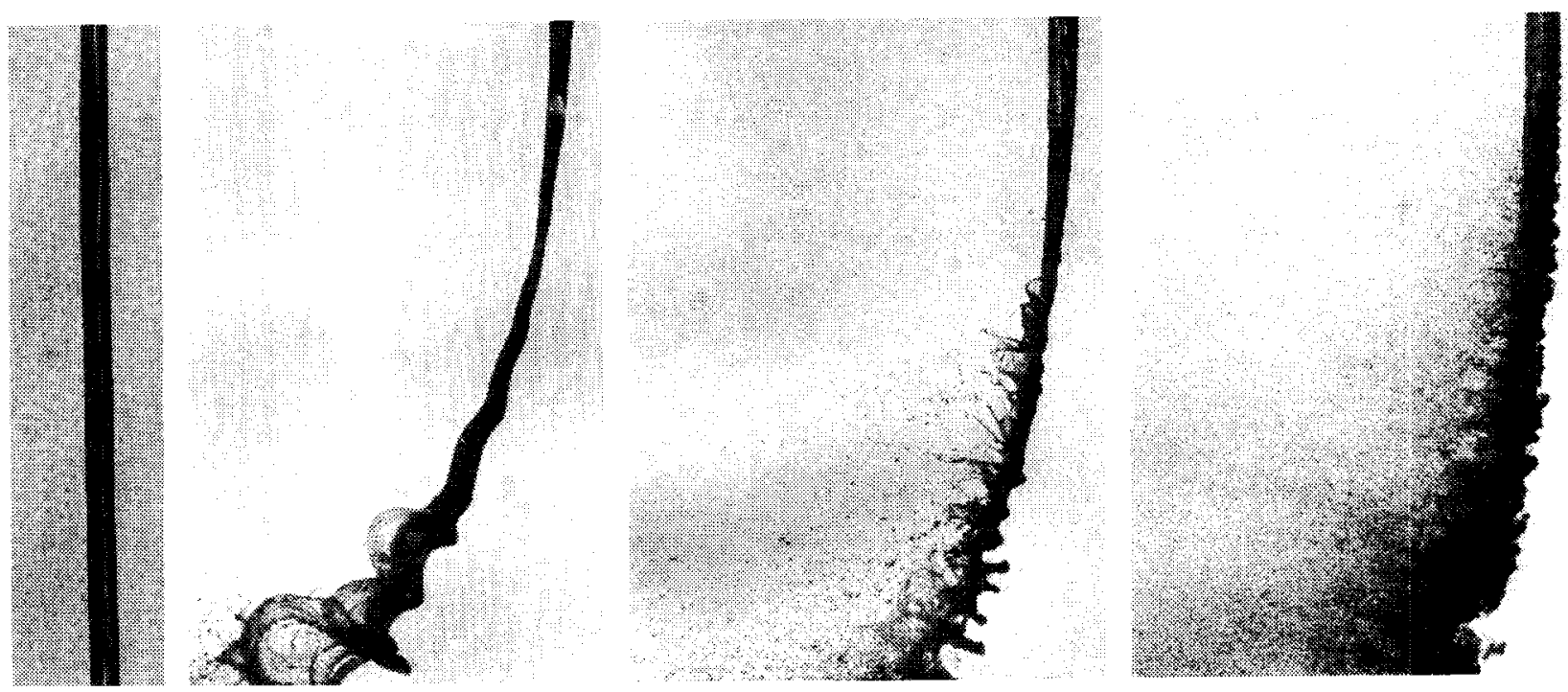

Fig. 2 Visualizations of nonturbulent round liquidjets in gas crossflows: $\mathrm{We}=0$, no breakup: $\mathrm{We}=8$, bag breakup: $\mathrm{We}=30$, multimode breakup: and $\mathrm{We}=220$. shear breakup . 


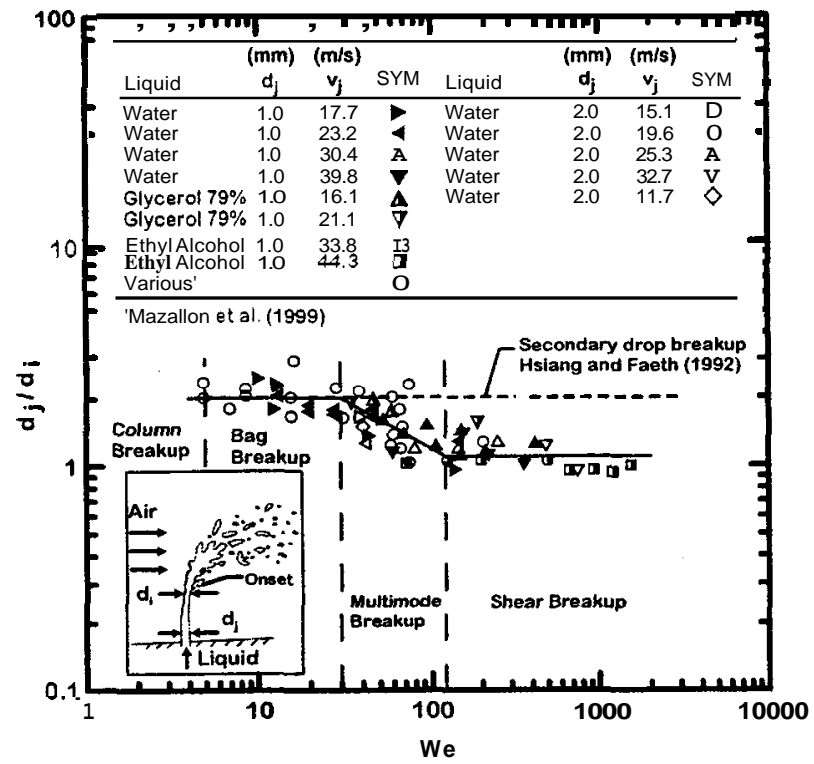

Fig. 4 Deformation at onset of primary breakup as a function of Weber number for nonturbulent round liquid jets in gas crossflows. Results from Mazallon et al. [1] and the present investigation.

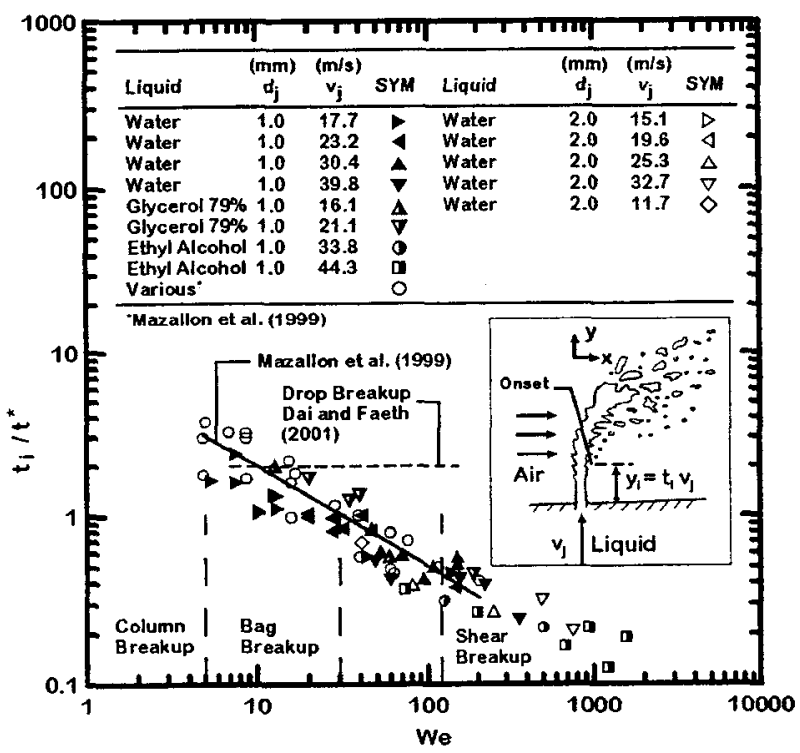

Fig. 5 Time of the onset of primary breakup as a function of Weber number for nonturbulent round liquid jets in gas crossflows. Results from Mazallon et al. [1] and the present investigation.

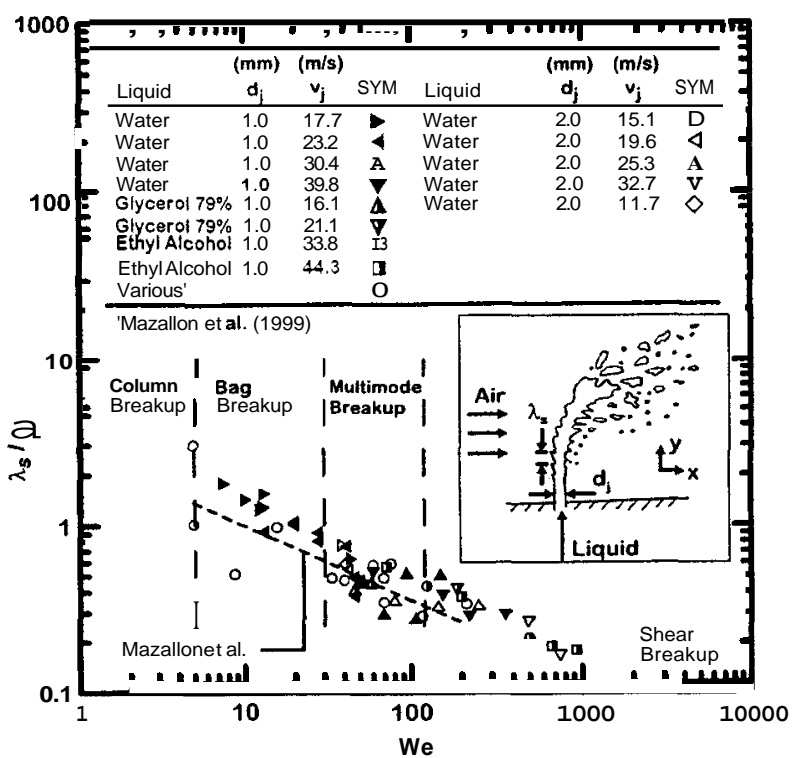

Fig. 6 Liquid surface wavelengths of nonturbulent round liquid jets in air crossflows. Results from Mazallon et al. [1] and the present investigation.

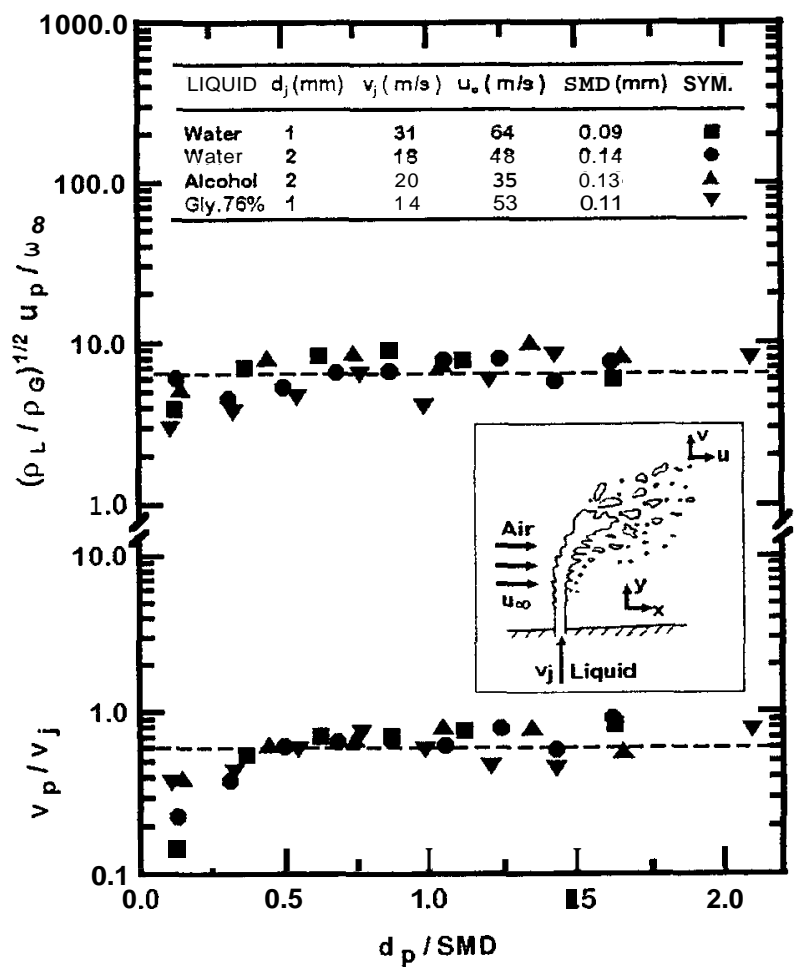

Fig. 7 Streamwise and crosstream drop velocity distributions after primary breakup of nonturbulent round liquid jets in air crossflows. 


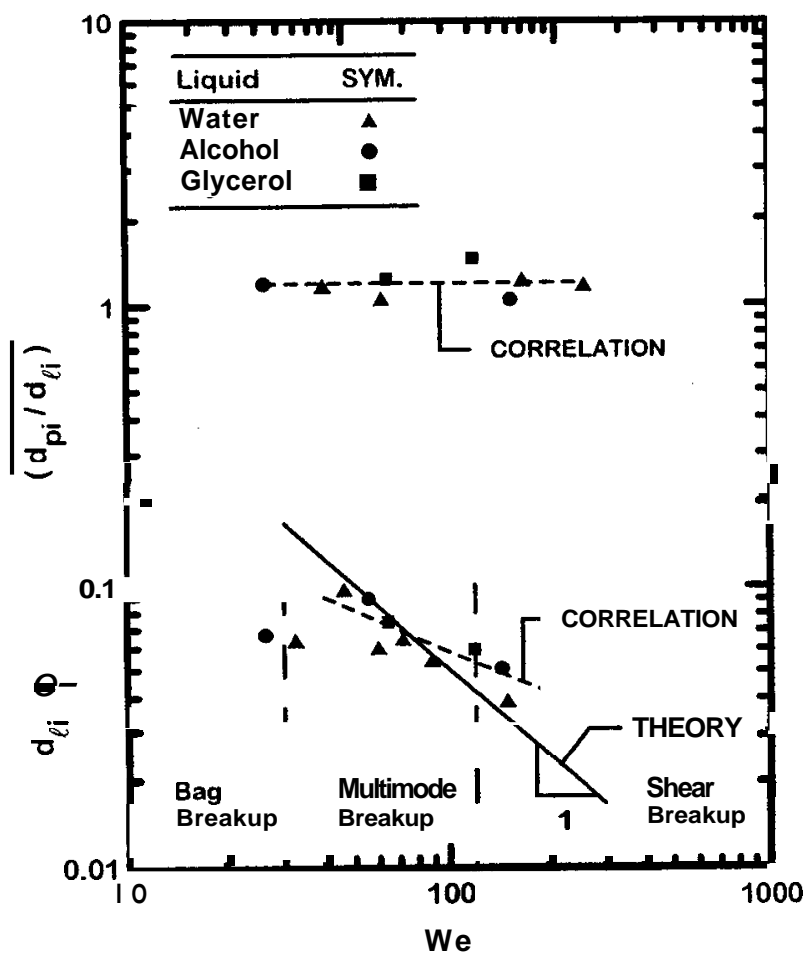

Fig. 8 Diameters of ligaments and drops at the onset of breakup for primary breakup of nonturbulent round liquid jets in air crossflows.

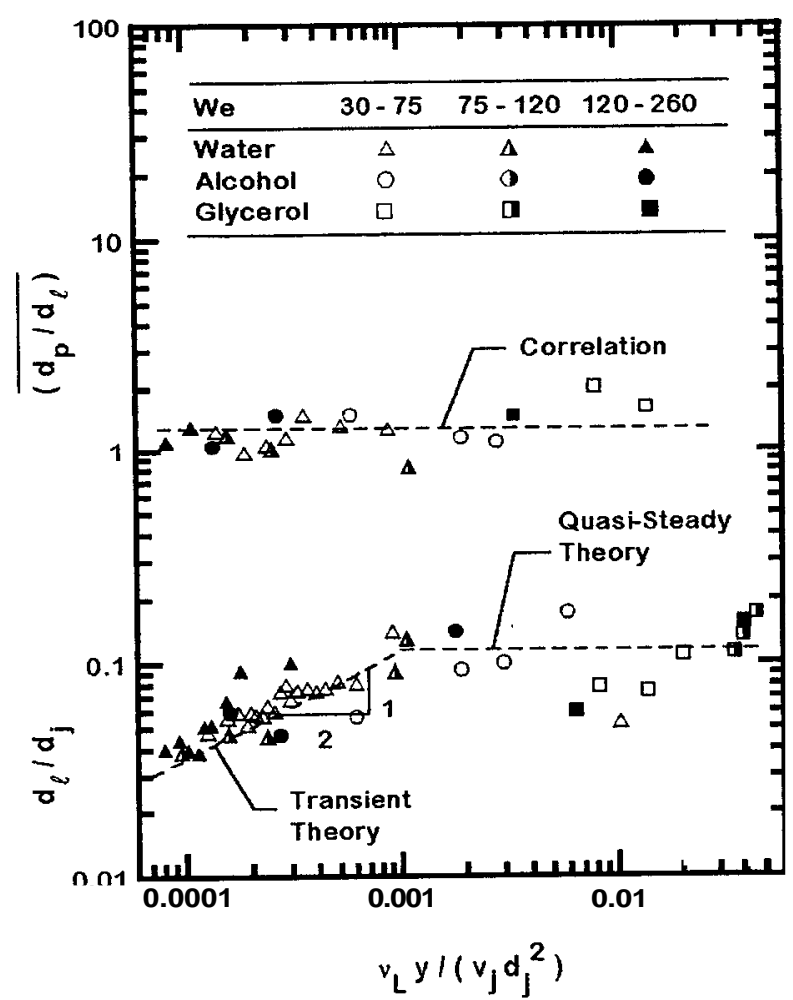

Fig. 9 Diameters of ligaments and drops as a function of time of jet flow (height) during primary breakup of nonturbulent round liquidjets in air crossflows.

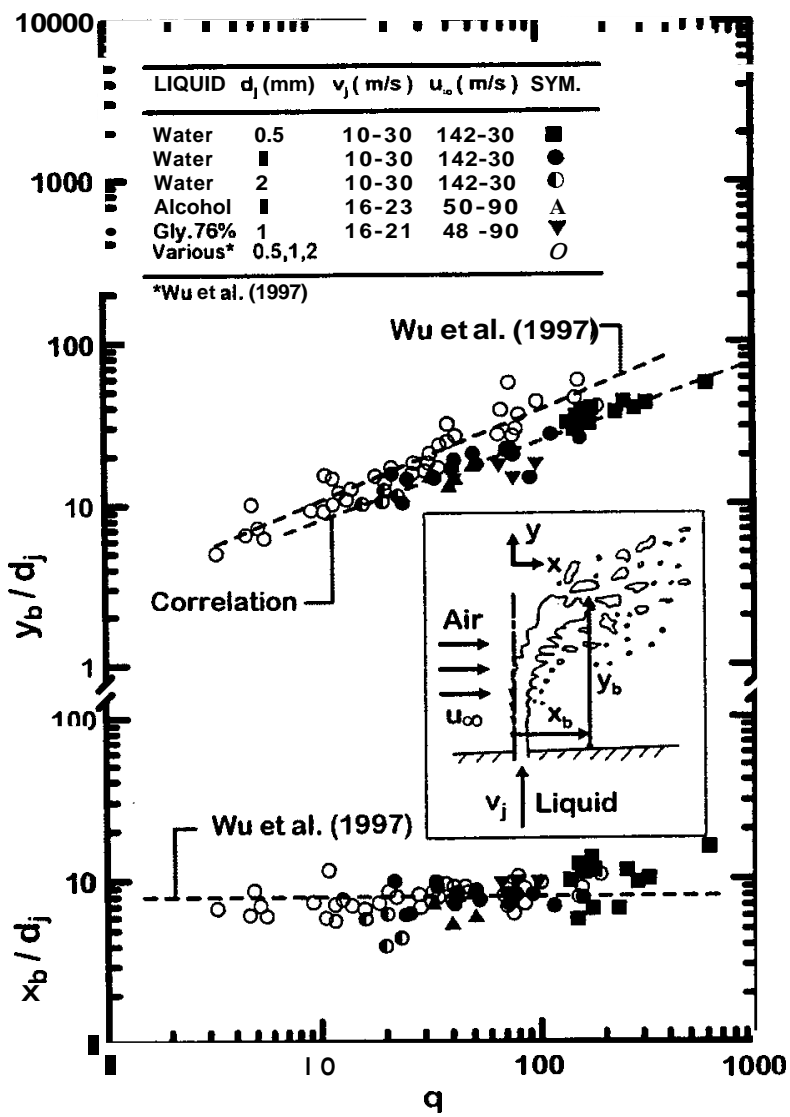

Fig. 10 Location of end of the liquid column in the streamwise and crosstream directions as a function of liquidgas momentum ratio during primary breakup of nonturbulent round liquid jets in air crossflows. 